\title{
The Unusual Suspect: A Case of Non-occlusive Mesenteric Ischemia in a Patient With Cirrhosis
}

\author{
Muhammad Z. Bawany ${ }^{\mathrm{a}, \mathrm{c}}$, Ali Nawras ${ }^{\mathrm{b}}$, Wael I. Youssef ${ }^{\mathrm{b}}$, Thomas Sodeman ${ }^{\mathrm{a}, \mathrm{b}}$
}

\begin{abstract}
Acute mesenteric ischemia has a variety of etiologies. Non-occulusive mesenteric ischemia accounts for $20-30 \%$ of patients with acute mesenteric ischemia. We describe a case of non-occulusive jejunal ischemia leading to infarction that occurred in a patient with cirrhosis and no previous history of cardiovascular disease.
\end{abstract}

Keywords: Non-occulusive mesenteric ischemia; Cirrhosis; Jejunal infarcation

\section{Introduction}

Acute mesenteric ischemia (AMI) has a variety of etiologies. Non-occulusive mesenteric ischemia (NOMI) accounts for $20-30 \%$ of patients with AMI [1]. We describe a case of nonocculusive mesenteric ischemia leading to infarction that occurred in a patient with cirrhosis.

\section{Case Report}

A 53 years old female was brought to emergency department with abdominal pain and altered mental status (AMS). Her medical history was significant for chronic alcoholism, to-

Manuscript accepted for publication September 2, 2010

${ }^{a}$ Division of Internal Medicine, University of Toledo Medical Center, Toledo, Ohio, USA

${ }^{b}$ Division of Gastroenterology and Hepatology, University of Toledo Medical Center, Toledo, Ohio, USA

${ }^{\mathrm{c}}$ Corresponding author: University of Toledo Medical Center, 3000

Arlington Avenue Mail Stop 1150, Toledo, OH 43614, USA.

Email: Muhammad.Bawany@utoledo.edu bacco abuse and hepatitis C. Her blood pressure upon presentation was 101/64 $\mathrm{mmHg}$, pulse 109 beats/min, respirations 22 breaths $/ \mathrm{min}$, oxygen saturation of $97 \%$ on 4 liters oxygen per minute and she was afebrile. On examination she had generalized yellow discoloration of the body. Abdominal examination was significant for right upper quadrant tenderness, hepatosplenomegaly and absence of bowel sounds. The rest of the examination was unremarkable.

Her initial laboratory showed $\mathrm{Hb} 14.5 \mathrm{~g} / \mathrm{dl}$, WBC 10.2 thousand $/ \mathrm{mm}^{3}$, platelets 106,000 thousand $/ \mathrm{mm}^{3}$, Na 116 $\mathrm{meq} / \mathrm{L}, \mathrm{K} 2.9 \mathrm{meq} / \mathrm{L}, \mathrm{BUN} 13 \mathrm{mg} / \mathrm{dl}$, Cr $2.7 \mathrm{mg} / \mathrm{dl}$, CK-MB $18 \mathrm{ng} / \mathrm{ml}$ and troponin $0.08 \mathrm{ng} / \mathrm{ml}$, ammonia $168 \mathrm{umol} / \mathrm{L}$, bilirubin $29.2 \mathrm{mg} / \mathrm{dl}$ with direct bilirubin of $18.5 \mathrm{mg} / \mathrm{dl}$, albu$\min 2.8 \mathrm{~g} / \mathrm{dl}$, INR 2.34, alkaline phosphatase $270 \mathrm{IU} / \mathrm{L}$, ALT $172 \mathrm{IU} / \mathrm{L}$, AST $679 \mathrm{IU} / \mathrm{L}$ and lactate of $10.5 \mathrm{mmol} / \mathrm{L}$. Abdominal ultrasound showed an enlarged liver with distended gall bladder. She was admitted to Intensive Care Unit (ICU) because of AMS. The patient started having coffee ground emesis within an hour of admission to the ICU. A nasogastric tube was placed which recovered $600 \mathrm{ml}$ of coffee ground aspirate. She gradually became hypotensive and was subsequently started on pressors.

The patient underwent an emergent esophagogastroduodenoscopy which revealed severe reflux esophagitis without active bleeding in the distal esophagus and no varices. The duodenum was erythematous and eccymotic, consistent with ischemia. General surgery was consulted and patient under-

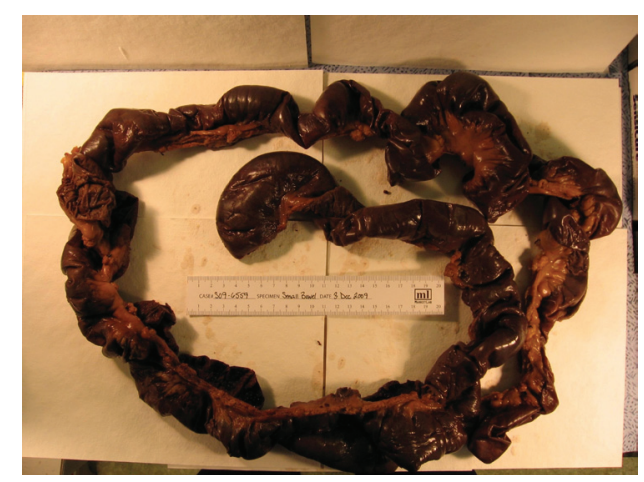

Figure 1. Gross specimen of resected small intestine. 


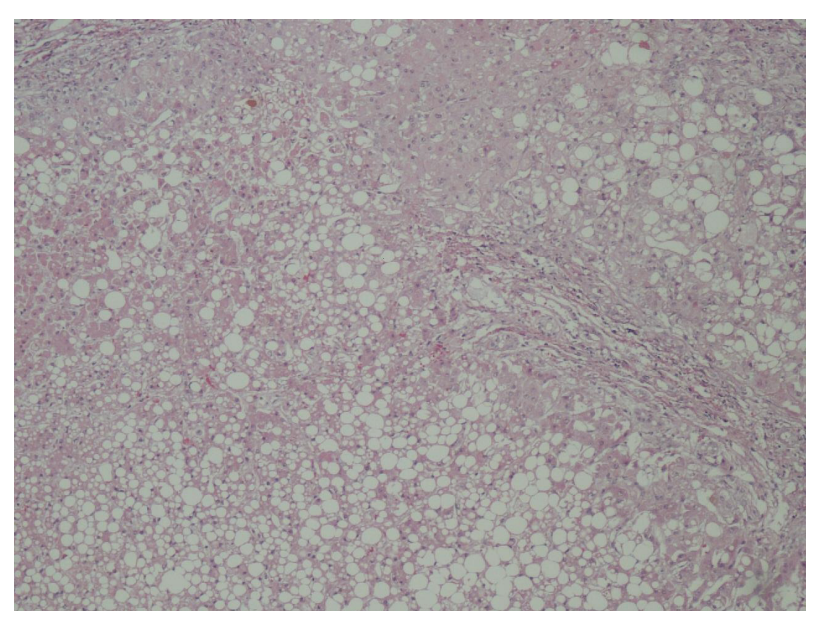

Figure 2. Liver biopsy showing macrosteatosis.

went an exploratory laparotomy which revealed dark brown serosa of jejunum $3 \mathrm{~cm}$ distal to the ligament of Treitz extending distally to approximately $180 \mathrm{~cm}$ sparing the ileum (Fig. 1). The infracted bowel was resected. Liver was found to be massively enlarged with multiple small nodules grossly suspected of cirrhosis and a needle biopsy was done. The colon was normal on visual inspection. Her abdomen was left open as her intestine was in discontinuity as well as for a possible second look in 24 - 48 hours.

Postoperatively the patient was continued on multiple pressors as she was still profoundly hypotensive. As her condition continued to decline and showed no signs of improvement on mechanical ventilation, support was withdrawn according to her wishes.

Pathology of the specimen showed an extensive full thickness ischemic necrosis of the intestine without any significant evidence of atherosclerosis or thrombus in the vessels, consistent with NOMI. The liver biopsy confirmed cirrhosis with macrovesicular steatosis and necrosis (Fig. 2).

\section{Discussion}

To our knowledge, this is the first case report of NOMI in a patient with cirrhosis. We postulate this to be secondary to elevated levels of neurohormonal mediators like vasopressin and angiotensin, as a result of abnormal metabolism, causing hypoperfusion and vasoconstriction [2].
NOMI commonly occurs in an elderly person with cardiovascular disease (CVD) on medical therapy, as opposed to our patient who was not on any medications for CVD. Cases have been reported with cocaine use [3, 4]; however, our patient's urine toxicology was negative. Mortality rate with NOMI is nearly $70 \%$, usually because of a delay in diagnosis and treatment for the causes of ischemia [5]. Small intestinal villous tips are most vulnerable to the ischemia and after 3 - 6 hours [6], this mucosal damage can lead to translocation of bacteria and sepsis [7].

This case is of particular interest because neither our patient had any history of CVD, which has been thought to be one of the risk factor for NOMI, nor she had a thrombus or significant atherosclerosis in her mesenteric vessel, which has been reported in the past to be the cause of mesenteric ischemia in a patient with cirrhosis. However, more work needs to be done to better understand the pathophysiology of NOMI in a patient with cirrhosis.

\section{References}

1. Trompeter M, Brazda T, Remy CT, Vestring T, Reimer P. Non-occlusive mesenteric ischemia: etiology, diagnosis, and interventional therapy. Eur Radiol 2002;12(5):11791187.

2. Wilcox MG, Howard TJ, Plaskon LA, Unthank JL, Madura JA. Current theories of pathogenesis and treatment of nonocclusive mesenteric ischemia. Dig Dis Sci 1995;40(4):709-716.

3. Sudhakar CB, Al-Hakeem M, MacArthur JD, Sumpio BE. Mesenteric ischemia secondary to cocaine abuse: case reports and literature review. Am J Gastroenterol 1997;92(6):1053-1054.

4. Endress C, Gray DG, Wollschlaeger G. Bowel ischemia and perforation after cocaine use. AJR Am J Roentgenol 1992;159(1):73-75.

5. Bassiouny HS. Nonocclusive mesenteric ischemia. Surg Clin North Am 1997;77(2):319-326.

6. Ritz JP, Runkel N, Berger G, Buhr HJ. [Prognostic factors in mesenteric infarct]. Zentralbl Chir 1997;122(5):332338.

7. Kolkman JJ, Groeneveld AB. Occlusive and non-occlusive gastrointestinal ischaemia: a clinical review with special emphasis on the diagnostic value of tonometry. Scand J Gastroenterol Suppl 1998;225(3-12. 